\title{
Exploring Possibility of the Chromium (Cr) Removal from Molten Aluminum by adding Boron Bearing Additive (Aluminum-Boron Master Alloy)
}

\author{
Abdul Khaliq ${ }^{1}$, Muhammad Akbar Rhamdhani ${ }^{2}$, Rahila Batul ${ }^{2}$ \\ 1. School of Engineering, RMIT University, Melbourne Australia \\ 2. Faculty of Science, Engineering and Technology, Swinburne University of Technology, Melbourne, \\ Australia
}

It is well documented that transition metals including chromium $(\mathrm{Cr})$ deteriorates electrical conductivity of the aluminum alloys. Concentration of the transition metals varies from few parts per million (ppm) to $1400 \mathrm{ppm}$ that are removed in casthouse by the addition of boron bearing substances and the process is called boron treatment. Aluminum- boron (Al-B) master alloys containing $\mathrm{AlB}_{2}$ or $\mathrm{AlB}_{12}$ are commonly used to tie up transition metals in solution to their stable borides. In our previous work, removal of the Zirconium $(\mathrm{Zr})$ and Vanadium $(\mathrm{V})$ from molten aluminum by inoculation with $\mathrm{Al}$ $\mathrm{B}\left(\mathrm{AlB}_{2}\right.$ and $\left.\mathrm{AlB}_{12}\right)$ has been reported $[1,2]$. Phase diagram analysis of $\mathrm{Al}-\mathrm{Cr}$ system showed that $\mathrm{Al}{ }_{7} \mathrm{Cr}$ is the stable phase in the $\mathrm{Al}-1 \mathrm{wt} \% \mathrm{Cr}$ at room temperature [3]. It has been reported that $\mathrm{Cr}$ forms series of borides $\left(\mathrm{CrB}_{2}, \mathrm{Cr}_{2} \mathrm{~B}, \mathrm{CrB}, \mathrm{Cr}_{3} \mathrm{~B}_{4}, \mathrm{Cr}_{5} \mathrm{~B}_{3}\right.$ and $\left.\mathrm{CrB}_{4}\right)$ in the $\mathrm{Cr}-\mathrm{B}$ binary system [4].

It has been reported that electrical conductivity of the smelter grade aluminum is increased by 22 times when $\mathrm{Cr}$ is removed from solution into borides or some other intermetallic structure. However, it is not yet clear in literature whether $\mathrm{Cr}$ can be isolated from molten aluminum similar to $\mathrm{Zr}$ and $\mathrm{V}$ in the form of their stable diborides $\left(\mathrm{CrB}_{2}\right)$. There are conflicting reports about the removal of $\mathrm{Cr}$ from molten that can be found elsewhere [5]. The aim of this paper is to explore the possibility of $\mathrm{Cr}$ removal from molten aluminum alloy by the adding $\mathrm{Al}-\mathrm{B}\left(\mathrm{AlB}_{12}\right)$ master alloy at $750^{\circ} \mathrm{C}$.

For this study, Al-1wt $\% \mathrm{Cr}$ alloy was prepared using induction furnace. Experimental setup and procedure is reported elsewhere [5]. Aluminum boron master alloy ingots containing $\mathrm{AlB}_{12}$ phase were added in the molten alloy. It was assumed $\mathrm{CrB}_{2}$ will form by reaction of $\mathrm{Cr}$ and $\mathrm{B}$ from $\mathrm{AlB}_{12}$. Alloy samples were taken at regular intervals and analyzed using scanning electron microscope (SEM) and inductively coupled plasma atomic emission spectroscopy (ICP-AES).

Figure 1(a) shows the SEM(SI) of Al-1wt\%Cr-0.415wt\%B alloy taken at 15 minutes after the addition of Al-B master alloys. There is no evidence of reaction product similar to that shown in Figure 1(b). In the case of reaction between $\mathrm{Cr}$ and $\mathrm{AlB}_{12} / \mathrm{B}$ there should be continuous or discontinuous layers of reaction product (Cr-borides) at interface. Energy dispersive X-ray (EDS) spectrum of position X (Figure 2(a)) revealed that the grey particles are made of $\mathrm{Al}$ and $\mathrm{Cr}$ which are most likely $\mathrm{Al}_{7} \mathrm{Cr}$. Such particles nucleated on the existing particles $\left(\mathrm{AlB}_{12} /\right.$ undissolved $\left.\mathrm{Al}_{7} \mathrm{Cr}\right)$ and aggregated during solidification process.

The concentration of $\mathrm{Cr}$ in the $\mathrm{Al}-1 \mathrm{wt} \% \mathrm{Cr}-0.415 \mathrm{wt} \% \mathrm{~B}$ alloy was determined by ICP and is plotted with melt holding $\left(\mathrm{Cr} / \mathrm{AlB}_{12}\right.$ reaction) time, as shown in Figure 2(b). Surprisingly the concentration of $\mathrm{Cr}$ in samples were much less than $1 \mathrm{wt} \%$ and also increased with time. This is due to the dissolution of $\mathrm{Al}_{7} \mathrm{Cr}$ intermetallic particles that releases $\mathrm{Cr}$ into molten alloy. Overall, there no evidence of decrease in $\mathrm{Cr}$ level with $\mathrm{Cr} / \mathrm{AlB}_{12}$ reaction time. Therefore, it may be not feasible to remove $\mathrm{Cr}$ from molten $\mathrm{Al}$ by 
adding Al-B master alloys. Existence of $\mathrm{Cr}$ in sludge as reported by previous investigators could be attributed due to presence of small Al-Cr intermetallic rather than borides.

\section{References}

[1] Khaliq, A. et al TMS Light Metals (2011), p. 751

[2] Khaliq, A. et al Journal of Metallurgical and Materials Transaction B, 2014, 45(2) p. 784

[3] Kurtuldu, G., P. Jessner, and M. Rappaz, Journal of Alloys and Compounds, 2015, 621, p. 283

[4] Campbell, C.E. and U.R. Kattner, Calphad, 2002. 26(3): p. 477

[5] Khaliq, A., PhD Thesis, Swinburne University of Technology Melbourne, 2014, p. 1-320
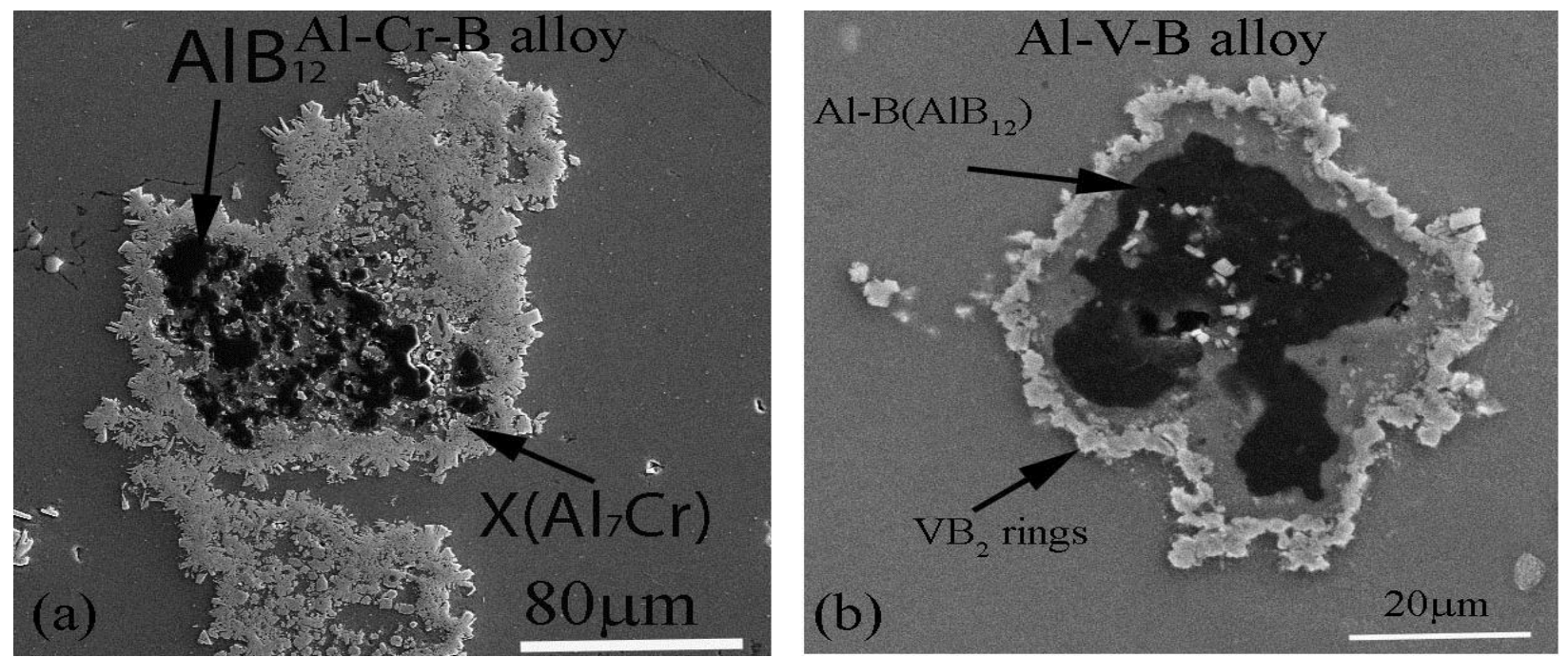

Figure 1. Scanning electron images (SI) of (a) Al-1wt\%Cr-0.415wt\%B and (b) Al-1wt\%V-0.721wt\%B alloys [5].
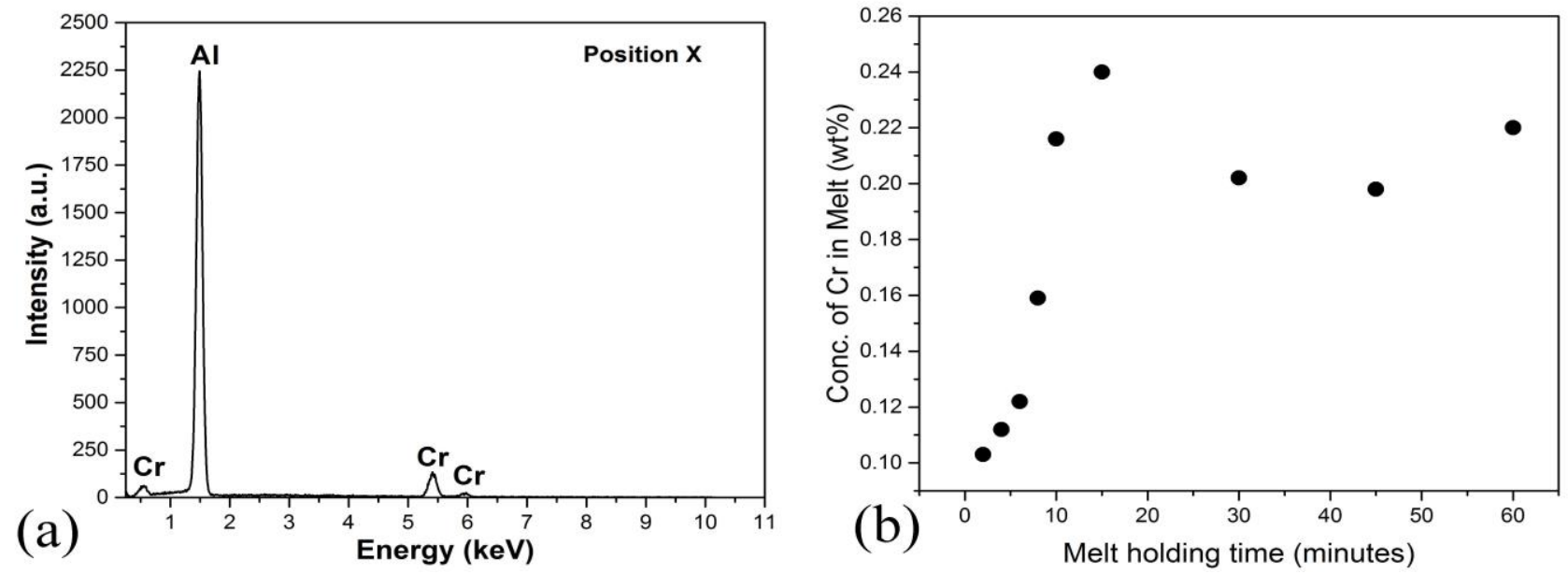

Figure 2. (a) EDS analysis of position $X$ (see Figure 1(a)) and (b) ICP analysis of $\mathrm{Cr}$ in molten Al$1 \mathrm{wt} \% \mathrm{Cr}-0.415 \mathrm{wt} \% \mathrm{~B}$ alloy 